\title{
Post-operative nausea and vomiting after gynecologic laparoscopic surgery: comparison between propofol and sevoflurane
}

\author{
Helen Ki Shinn, Mi Hyeon Lee, Sin Yeong Moon, Sung-Il Hwang, Choon Soo Lee, Hyun Kyoung Lim, \\ and Jang-Ho Song \\ Department of Anesthesiology and Pain Medicine, College of Medicine, Inha University, Incheon, Korea
}

Background: We compared the incidence and degree of post-operative nausea and vomiting (PONV) in patients who received general anesthesia with propofol or sevoflurane using the Rhodes index of nausea, vomiting, and retching (RINVR) to assess the degree of PONV quantitatively and objectively during the post-anesthetic period.

Methods: We performed a prospective study involving 38 patients who underwent gynecologic laparoscopic surgery in our hospital between September 2008 and August 2009. Nineteen patients were anesthetized with propofol during the entire anesthetic period and the other 19 patients received $2.0 \mathrm{mg} / \mathrm{kg}$ of propofol intravenously, followed by sevoflurane inhalation. Three patients who were anesthetized with sevoflurane were excluded from the analysis because they were omitted during the survey. We studied the patients who had PONV and RINVR scores 1, 6, and 24 hours post-operatively.

Results: The propofol group had a statistically lower incidence of PONV and lower RINVR scores in the following subclasses within 1 hour of surgery: symptom occurrence; symptom distress; and symptom experience.

Conclusions: Propofol at induction and during maintenance of anesthesia can be used to prevent PONV within 1 hour post-operatively in patients undergoing gynecologic laparoscopic surgery. (Korean J Anesthesiol 2011; 60: 36-40)

Key Words: Laparoscopic surgery, Post-operative nausea and vomiting, Propofol, Sevoflurane.

Received: June 3, 2010. Revised: 1st, June 17, 2010; 2nd, July 19, 2010. Accepted: August 8, 2010.

Corresponding author: Jang-Ho Song, M.D., Department of Anesthesiology and Pain Medicine, College of Medicine, Inha University, 7-206, Sinheung-dong 3-ga, Jung-gu, Incheon 400-711, Korea. Tel: 82-32-890-3968, Fax: 82-32-881-2477, E-mail: snoguy@naver.com This work was supported by Inha University.

(c) This is an open-access article distributed under the terms of the Creative Commons Attribution Non-Commercial License (http:// creativecommons.org/licenses/by-nc/3.0/), which permits unrestricted non-commercial use, distribution, and reproduction in any medium, provided the original work is properly cited. 


\section{Introduction}

The incidence of post-operative nausea and vomiting (PONV) in patients who undergo operations in which general anesthesia is administered has been reported to range $20-30 \%$ [1]. PONV results in some of the most severe discomfort amongst patients, along with post-operative pain. The causes of PONV are many and varied based on patient, and surgery-, and anesthesiarelated factors, and PONV occurs frequently in patients undergoing gynecologic laparoscopic surgery [1]. With respect to anesthetic agents, nitrous oxide and volatile anesthetics increase the occurrence of PONV, but propofol is known to have an anti-emetic effect $[1,2]$.

The Rhodes index of nausea, vomiting, and retching (RINVR) is a method of quantifying nausea and vomiting objectively in patients who receive anti-cancer therapy. Compared with the method of simply detecting PONV occurrence or with the method of measuring the degree of PONV subjectively using a visual analogue scale (VAS), RINVR is a more suitable method for quantitatively and objectively assessing the degree of PONV that patients may feel [3].

However, research which has compared the degree of PONV after general anesthesia with propofol or sevoflurane at each set time during the post-anesthetic period using RINVR is limited.

Thus, the purpose of this study was to compare the number of patients who have symptoms of PONV and the objective degree of PONV which occurs after general anesthesia with propofol or sevoflurane at each set time during the post-anesthetic period in patients with multiple risk factors for PONV, such as female gender, gynecologic laparoscopic surgery, and post-operative opioid therapy.

\section{Materials and Methods}

After obtaining approval of the Institutional Review Board of our hospital, female patients who were admitted to the Department of Obstetrics and Gynecology between September 2008 and August 2009 and underwent laparoscopic total hysterectomy and laparoscopy-assisted vaginal hysterectomy were included in this study. The subjects of our study were patients who were between 19 and 69 years of age and classified as American Society of Anesthesiologists physical status I or II. Patients who had a history of PONV or motion sickness were excluded. At the preoperative visit, anesthesiologists obtained written informed consent from each patient after explaining the methods and the purpose of this study, but did not administer pre-medication. We classified patients who were anesthetized with propofol as group $\mathrm{P}$ and the other patients who were anesthetized with sevoflurane as group S. The patients were alternately assigned to the groups according to the order in which they came to the hospital. Thirty-eight patients were included in this study; 19 patients were assigned to groups $\mathrm{P}$ and $\mathrm{S}$. Three patients who were anesthetized with sevoflurane were excluded from the analysis because they were omitted during the survey.

The age, height, weight, BMI, pre-operative hemoglobin level, total amount of fluid administered during surgery, total anesthesia and operative times, and visual analogue scale (VAS) scores of the patients in both groups at each set time during the post-anesthetic period are shown in Table 1.

In the group P patients, $4.0-5.0 \mu \mathrm{g} / \mathrm{ml}$ of propofol and $1.5 \mathrm{ng} /$ $\mathrm{ml}$ of remifentanil were injected intravenously using a targetcontrolled infusion (TCI) to induce general anesthesia. After confirming loss of consciousness, we injected $0.6 \mathrm{mg} / \mathrm{kg}$ of rocuronium intravenously and intubated the patient 3 minutes after injection. The anesthesia was maintained with propofol and remifentanil and the concentration of TCI was controlled to keep the blood pressure within a $20 \%$ range of the baseline blood pressure. In group S patients, $2.0 \mathrm{mg} / \mathrm{kg}$ of propofol was injected intravenously and $1.5 \mathrm{ng} / \mathrm{ml}$ of remifentanil was infused continuously using TCI to induce general anesthesia. After confirming loss of consciousness, sevoflurane (3 vol\%) was administered via facial mask. Then, we injected $0.6 \mathrm{mg} / \mathrm{kg}$ of rocuronium intravenously and intubated the patient 3 minutes thereafter. The anesthesia was maintained with continuous infusion of remifentanil by TCI and sevoflurane inhalation, and the concentration of anesthetic agents was controlled to maintain the blood pressure within a $20 \%$ range of the baseline blood pressure. All patients were intubated without difficulty and maintained at a $\mathrm{FiO}_{2}$ of 0.5 using air-oxygen. The patients in both groups were injected with $1 \mu \mathrm{g} / \mathrm{kg}$ of fentanyl and 30 mg of ketorolac intravenously for post-operative pain control 30 minutes before the surgical procedure was completed. Then, intravenous, patient-controlled analgesia $(24 \mu \mathrm{g} / \mathrm{kg}$ of fentanyl and $8 \mathrm{mg}$ of ondansetron) was initiated.

Table 1. Patient Characteristics, Procedure Factors, and Visual Analogue Scale after Surgery

\begin{tabular}{lcc}
\hline & Group P (n=19) & Group S (n=16) \\
\hline Age $(\mathrm{yr})$ & $38.6 \pm 11.7$ & $41.9 \pm 8.9$ \\
Height $(\mathrm{cm})$ & $156.5 \pm 5.3$ & $159.0 \pm 5.0$ \\
Weight $(\mathrm{kg})$ & $58.0 \pm 7.2$ & $60.0 \pm 8.7$ \\
BMI & $23.7 \pm 3.1$ & $23.7 \pm 3.0$ \\
Pre-operative Hb (g/dl) & $12.3 \pm 1.5$ & $12.3 \pm 1.2$ \\
Total fluids during surgery (ml) & $976 \pm 446$ & $872 \pm 350$ \\
Total anesthesia times (min) & $154 \pm 50$ & $145 \pm 50$ \\
Total operation times (min) & $121 \pm 49$ & $118 \pm 55$ \\
VAS, 1 hour after surgery & $4.5 \pm 1.9$ & $4.63 \pm 1.9$ \\
VAS, 6 hours after surgery & $2.5 \pm 1.8$ & $2.3 \pm 2.3$ \\
VAS, 24 hours after surgery & $1.7 \pm 1.2$ & $1.1 \pm 1.0$ \\
\hline
\end{tabular}

Values are the mean \pm SD. Group P is the propofol group. Group $S$ is the sevoflurane group. There were no significant difference between the two groups. 
PONV assessment was made by an anesthesiologist using the questionnaire at 1,6 , and 24 hours post-operatively using the RINVR (Table 2). The RINVR consisted of 8 questions; each question had 5 examples, and the patients were asked to mark the example that applied to them personally. We scored each example of every question on a scale of 0 (the symptom was none or mild) to 4 (the symptom was a lot or severe). After the questionnaire was completed, the scores of examples that each patient marked were summed and categorized as follows: subclass of symptom occurrence (SOSO; question numbers 1 , $4,6,7$, and 8), which focused on the occurrence of symptoms; subclass of symptom distress (SOSD; question numbers 2, 3 , and 5), which focused on the distress of symptoms; and subclass of symptom experience (SOSE; all 8 questions). The calculated scores of the two groups were compared according to each subclass at each set time during the post-anesthetic period. Also, when the RINVR score was $\geq 1$, we presumed that PONV occurred. The number of patients who had PONV during the 24 hours after the surgical procedure and at each set time during the post-anesthetic period was calculated and the number of the patients in the two groups was compared to each other. Even if 1 person experienced PONV several times during the 24-hour post-operative period, we considered it as one person.

Assuming the incidence of PONV within 24 hours following gynecologic surgery using volatile anesthetics to be $45 \%$ and the $40 \%$ difference in the incidence of PONV between the 2 groups as clinically significant, we calculated the number of patients in the current study based on an existing study [4]. As we defined the incidence of PONV within 24 hours after surgery to be the primary outcome of this study, we calculated that 16 patients would be required in each group to achieve an $80 \%$ statistical power at a $5 \%$ significance level to detect a true difference between the 2 groups. Assuming the possibility of being dropped out during the study, we decided to choose 19 patients per group.

The statistical analysis was done using SPSS (version 12.0; SPSS, Inc., Chicago, IL, USA). Age, height, weight, BMI, preoperative hemoglobin level, total amount of fluids administered during surgery, total anesthesia time, and VAS score of each set time during the post-anesthetic period in both groups were analyzed using an unpaired t-test. The RINVR scores of each set time during the post-anesthetic period were analyzed by the Mann-Whitney U test. The number of patients who had symptoms of PONV at each set time during the post-anesthetic period and the total number of patients during 24 hours after surgery were analyzed by Fisher's exact test. A statistically significant difference was assumed for a $\mathrm{P}<0.05$.

\section{Results}

The RINVR scores for SOSO, SOSD, and SOSE 1 hour postoperatively were significantly lower in group $\mathrm{P}$ than group $\mathrm{S}$, but there was no difference at 6 and 24 hours postoperatively (Table 3 ).

The incidence of PONV during the 24 hours post-operatively was $15.8 \%$ (3 patients) in group $\mathrm{P}$ and $75.0 \%$ (12 patients) in group S; thus, the incidence of PONV in group $\mathrm{P}$ during the first 24 hours post-operatively was significantly lower than group S. In each set time during the post-anesthetic period, the number of patients with symptoms of PONV within 1 hour post-operatively in group $\mathrm{P}$ was $5.3 \%$ (1 patient) and $62.5 \%$ (10 patients) in group S; thus, the number of patients with symptoms of PONV within 1 hour post-operatively in group P was significantly lower than group S, but there was no

Table 2. A Questionnaire for the Rhodes Index of Nausea, Vomiting, and Retching (RINVR) at N Hours after Surgery

\begin{tabular}{|c|c|c|c|c|c|}
\hline Scores & 4 & 3 & 2 & 1 & 0 \\
\hline 1. In the last $\mathrm{N}$ hours, I threw up __ times. & 7 or more & $5-6$ & $3-4$ & $1-2$ & $\begin{array}{l}\text { I did not } \\
\text { throw up }\end{array}$ \\
\hline $\begin{array}{l}\text { 2. In the last } \mathrm{N} \text { hours, from retching and dry heaves, } \\
\text { I felt _ distress. }\end{array}$ & Severe & Great & Moderate & Mild & No \\
\hline $\begin{array}{l}\text { 3. In the last N hours, from vomiting or throwing up, } \\
\text { I have felt__ distress. }\end{array}$ & Severe & Great & Moderate & Mild & No \\
\hline $\begin{array}{l}\text { 4. In the last } \mathrm{N} \text { hours, I have felt nauseated or } \\
\text { sick to my stomach }\end{array}$ & $\begin{array}{l}\text { More than } 4 \\
\text { hours }\end{array}$ & $2-3$ hours & $1-2$ hours & 1 hour less & Not at all \\
\hline $\begin{array}{l}\text { 5. In the last } \mathrm{N} \text { hours, because of nausea/sickness, } \\
\text { I have felt _ distress. }\end{array}$ & Severe & Great & Moderate & Mild & No \\
\hline $\begin{array}{l}\text { 6. In the last } \mathrm{N} \text { hours, each time I threw up, } \\
\text { I produced a _ amount. }\end{array}$ & $\begin{array}{c}\text { Very large } \\
\text { (3 cups or more) }\end{array}$ & $\begin{array}{c}\text { Large } \\
(2-3 \text { cups })\end{array}$ & $\begin{array}{c}\text { Moderate } \\
(1 / 2-2 \text { cups })\end{array}$ & $\begin{array}{l}\text { Small } \\
\text { (up to } 1 / 2 \text { cup) }\end{array}$ & $\begin{array}{l}\text { I did not } \\
\text { throw up }\end{array}$ \\
\hline $\begin{array}{l}\text { 7. In the last } \mathrm{N} \text { hours, I have felt nauseated or sick } \\
\text { to my stomach__ times. }\end{array}$ & 7 or more & $5-6$ & $3-4$ & $1-2$ & No \\
\hline $\begin{array}{l}\text { 8. In the last } \mathrm{N} \text { hours, I have had periods of retching } \\
\text { or dry heaves without bringing anything up _ times. }\end{array}$ & 7 or more & $5-6$ & $3-4$ & $1-2$ & No \\
\hline
\end{tabular}

$\mathrm{N}$ is 1,6 , and $24 \mathrm{~h}$ in this study. 
Table 3. Scores of Rhodes Index of Nausea, Vomiting, and Retching (RINVR)

\begin{tabular}{lccc}
\hline & $\begin{array}{c}\text { Subclass of } \\
\text { RINVR }\end{array}$ & $\begin{array}{c}\text { Group P } \\
(\mathrm{n}=19) \\
\text { Mean }\end{array}$ & $\begin{array}{c}\text { Group S } \\
(\mathrm{n}=16) \\
\text { Mean }\end{array}$ \\
\hline Within 1 h after surgery & SOSO & $0.0 \pm 0.0^{*}$ & $1.8 \pm 2.4$ \\
& SOSD & $0.1 \pm 0.2^{*}$ & $2.3 \pm 2.6$ \\
Between 1 and $6 \mathrm{~h}$ & SOSE & $0.1 \pm 0.2^{*}$ & $4.1 \pm 4.8$ \\
after surgery & SOSO & $0.3 \pm 0.9$ & $0.8 \pm 1.5$ \\
Between 6 and 24 h & SOSD & $0.2 \pm 0.7$ & $0.9 \pm 1.9$ \\
after surgery & SOSE & $0.4 \pm 1.6$ & $1.7 \pm 3.4$ \\
& SOSO & $0.0 \pm 0.0$ & $0.0 \pm 0.0$ \\
& SOSD & $0.0 \pm 0.0$ & $0.0 \pm 0.0$ \\
& SOSE & $0.0 \pm 0.0$ & $0.0 \pm 0.0$ \\
\hline
\end{tabular}

Values are the mean \pm SD. Group P is the propofol group. Group S is the sevoflurane group. SOSO: subclass of symptom occurrence. SOSD: subclass of symptom distress. SOSE: subclass of symptom experience. *Significantly different from group $\mathrm{S}, \mathrm{P}<0.05$.

difference between 1 and 6 hours, and 6 and 24 hours after postoperatively (Table 4).

\section{Discussion}

In addition to post-operative pain, PONV is among the most severe discomfort experienced by patients post-operatively. Apfel et al. [5] considered female gender, non-smokers, a history of PONV and motion sickness, and post-operative opioid therapy as important independent causal factors for PONV. Laparoscopic surgery is also known to increase the incidence of PONV [1]. The patients included in the current study had at least 3 risk factors for PONV, including female gender, laparoscopic surgery, and post-operative opioid therapy.

In the current study, we used RINVR scores to assess PONV. The RINVR score has been suggested to assess the degree of nausea and vomiting objectively in patients under treatment for cancer [6,7]. Kim et al. [3] reported that assessing PONV with RINVR objectively and quantitatively is a reliable index.

The incidence of PONV during the first 24 hours postoperatively in the case of propofol was significantly lower than sevoflurane (Table 4), and corresponds to the existing results that have been established for the anti-emetic effect of propofol [8].

While the number of patients with PONV within 1 hour postoperatively in the case of propofol was significantly less than sevoflurane, there were no differences in the number of patients with symptoms of PONV from 1-6 hours and 6-24 hours postoperatively. The results of assessing PONV with RINVR scores in the case of propofol were significantly lower than sevoflurane at 1 hour post-operatively only and there were no differences in RINVR scores at 6 and 24 hours post-operatively between the 2 groups. Apfel et al. [9] reported that volatile anesthetics
Table 4. The Number of Patients with Symptoms of PONV at Each Set Time during the Post-anesthetic Period

\begin{tabular}{lcc}
\hline & Group P $(\mathrm{n}=19)$ & Group S $(\mathrm{n}=16)$ \\
\cline { 2 - 3 } & $\operatorname{PONV}(+)$ & $\operatorname{PONV}(+)$ \\
\hline Within $1 \mathrm{~h}$ after surgery & $1(1)^{*}$ & $10(10)$ \\
Between 1 and 6 h after surgery & $2(2)$ & $5(2)$ \\
Between 6 and 24 h after surgery & $0(0)$ & $0(0)$ \\
Within 24 h after surgery & $3(3)^{*}$ & $12(12)$
\end{tabular}

Values before the parentheses are the numbers of patients with symptoms of PONV at each set time during the post-anesthetic period. Values in parentheses are the numbers of patients with newly developed symptoms of PONV at each set time during the post-anesthetic period. PONV: post-operative nausea and vomiting. Group P is the propofol group. Group S is the sevoflurane group. *Significantly different from group $\mathrm{S}$ and $\mathrm{P}<0.05$.

were the main cause of nausea and vomiting within 2 hours post-operatively. Because of the short duration of action, it is known that propofol does not show enough anti-emetic effect for PONV, which occurs after the patient is transferred to the general ward [10]. Because the patients in group P were anesthetized with propofol, which has an anti-emetic effect, and in group $\mathrm{S}$ with volatile anesthetics, which causes early PONV, it seems that the RINVR score 1 hour post-operatively in patients administered propofol was significantly lower than that in patients administered sevoflurane; however, there was no difference in the RINVR scores between the 2 groups after 1 hour because the effect of volatile anesthetics in patients with sevoflurane decreased after 1 hour.

In the current study, the number of patients who had newly developed PONV 1 hour post-operatively was 2 each for propofol and sevoflurane. Because the context-sensitive half-time of propofol and remifentanil is 30 and 3 minutes, respectively [11], when the average anesthesia time is 3 hours, we reasoned that the new onset PONV in 2 patients who received propofol 1-6 hours post-operatively was due to factors other than anesthesia, such as gynecologic surgery, laparoscopic surgery, or pain $[1,12]$. Similarly, we suggest that the majority of patients who had received with sevoflurane had PONV within 1 hour postoperatively because of residual volatile anesthetics. Because the time required to reduce the partial pressure of sevoflurane in the alveola to $90 \%$ is $<30$ minutes [13] when the average anesthesia time is 3 hours, we reasoned that the 2 patients with new onset PONV 1-6 hours post-operatively in the case of sevoflurane also had PONV not because of the effect of the residual volatile anesthetics, but because of factors other than anesthesia. There were no patients with new onset PONV 6 hours post-operatively in the 2 groups because factors other than anesthesia lost effect as time went by.

Thirty minutes before the end of the surgical procedure, all of 
the patients were injected with $1 \mu \mathrm{g} / \mathrm{kg}$ of fentanyl intravenously for post-operative pain control, and intravenous patientcontrolled analgesia, which was mixed with $24 \mu \mathrm{g} / \mathrm{kg}$ of fentanyl and $8 \mathrm{mg}$ of ondansetron. According to Ding and White's study [14], the analgesic dose of fentanyl used during the surgical procedure does not increase PONV and an ondansetron infusion using intravenous patient-controlled analgesia is known to be effective in preventing PONV.

At 1 hour post-operatively, most of the patients are in the post-anesthetic care unit or on general ward immediately after being transferred. During this period, the incidence of PONV owing to the effect of residual volatile anesthetics is high. Therefore, a lower RINVR score in the case of using propofol than sevoflurane within 1 hour following surgery is clinically important.

In conclusion, total intravenous anesthesia with propofol in gynecologic laparoscopic surgery is more effective than inhalation anesthesia using sevoflurane for decreasing PONV within 1 hour post-operatively.

\section{References}

1. Watcha MF, White PF. Postoperative nausea and vomiting. Its etiology, treatment, and prevention. Anesthesiology 1992; 77: 16284.

2. Fredman B, Nathanson MH, Smith I, Wang J, Klein K, White PF. Sevoflurane for outpatient anesthesia: a comparison with propofol. Anesth Analg 1995; 81: 823-8.

3. Kim TH, Choi BM, Chin JH, Lee MS, Kim DH, Noh GJ. The reliability and validity of the Rhodes index of nausea, vomiting and retching in postoperative nausea and vomiting. Korean J Anesthesiol 2007;
52: S59-65.

4. Apfel CC, Kranke P, Eberhart LH. Comparison of surgical site and patient's history with a simplified risk score for the prediction of postoperative nausea and vomiting. Anaesthesia 2004; 59: 1078-82.

5. Apfel CC, Läärä E, Koivuranta M, Greim CA, Roewer N. A simplifed risk score for predicting postoperative nausea and vomiting : conclusions from cross-validations between two centers. Anesthesiology 1999; 91: 693-700.

6. Rhodes VA. Criteria for assessment of nausea, vomiting, and retching. Oncol Nurs Forum 1997; 24: 13-9.

7. Rhodes VA, McDaniel RW. The index of nausea, vomiting, and retching: a new format of the index of nausea and vomiting. Oncol Nurs Forum 1999; 26: 889-94.

8. Sneyd JR, Carr A, Byrom WD, Bilski AJ. A meta-analysis of nausea and vomiting following maintenance of anaesthesia with propofol or inhalational agents. Eur J Anaesthesiol 1998; 15: 433-45.

9. Apfel CC, Kranke P, Katz MH, Goepfert C, Papenfuss T, Rauch S, et al. Volatile anaesthetics may be the main cause of early but not delayed postoperative vomiting: a randomized controlled trial of factorial design. Br J Anaesth 2002; 88: 659-68.

10. Jokela RM, Kangas-Saarela TA, Valanne JV, Koivuranta MK, Ranta PO, Alahuhta SM. Postoperative nausea and vomiting after sevoflurane with or without ondansetron compared with propofol in female patients undergoing breast surgery. Anesth Analg 2000; 91: 1062-5.

11. Miller RD. Miller's anesthesia. 7th ed. Philadelphia, Elsevier Churchill Livingstone. 2005, p 840.

12. Islam S, Jain PN. Post-operative nausea and vomiting (PONV): a review article. Indian J Anaesth 2004; 48: 253-8.

13. Miller RD. Miller's anesthesia. 7th ed. Philadelphia, Elsevier Churchill Livingstone. 2005, p 556.

14. Ding Y, White PF. Comparative effects of ketorolac, dezocine, and fentanyl as adjuvants during outpatient anesthesia. Anesth Analg 1992; 75: 566-71. 